\title{
Experimental Study of Small-Scale Mineral Particles in the Atmosphere of Central Asia
}

\author{
V. V. Adushkin ${ }^{a, b}$, B. B. Chen ${ }^{c}$, S. I. Popel ${ }^{b, d, e, ~ *, ~ A . ~ Y u . ~ D u b i n s k i i ~}{ }^{d}$, P. G. Weidler ${ }^{f}$, and F. Friedrich $f$ \\ ${ }^{a}$ Institute of Geosphere Dynamics, Russian Academy of Sciences, Moscow, 119334 Russia \\ ${ }^{b}$ Moscow Institute of Physics and Technology (State University), Dolgoprudnyi, Moscow Region, 141701 Russia \\ ${ }^{c}$ Kyrgyz Russian Slavic University, Bishkek, 720000 Kyrgyzstan \\ ${ }^{d}$ Space Research Institute, Russian Academy of Sciences, Moscow, 117997 Russia \\ ${ }^{e}$ National Research University Higher School of Economics, Moscow, 101000 Russia \\ ${ }^{f}$ Karlsruhe Institute of Technology, Campus North, Eggenstein-Leopoldshafen, D-76344 Karlsruhe, Germany \\ *e-mail:s_i_popel@mail.ru
}

\begin{abstract}
An experimental study of small-scale mineral particles in the atmosphere over Kyrgyzstan is carried out. It is shown that the substance of the studied particles corresponds to quartz-enriched minerals, feldspars, layered silicates, minerals containing lime carbonate, etc. Overall, there is a definite correspondence between the mineral particle compositions in the atmosphere of Kyrgyzstan and in the other regions of Central Asia. The constructed size-distribution functions of the particles agree with the results of studying the dust aerosol properties in the deserts of Central Asia obtained in the southwestern part of Tajikistan in 1989.
\end{abstract}

Keywords: small-scale mineral particles, Central Asia, adhesion, electron microscopy, energy-dispersive $\mathrm{X}$-ray analysis

Fine-dispersed particles fundamentally affect the climate and biosphere because of their influence on the process of the solar energy distribution above the Earth (Kondrat'ev et al., 1983; Anastasio and Martin, 2001; Popel et al., 2011). Our understanding of the role played by small-scale particles in the climate-controlling processes (and, hence, our investigations associated with these particles) rely on our knowledge of the chemical and physical characteristics of the latter. At present, as part of the scientific cooperation between Russia, Kyrgyzstan, and Germany, we study the aerosol particles, atmospheric brown clouds (ABCs) and their manifestations in Central Asia. The studies include both the experiments and theoretical work. The procedure for acquiring and analyzing nanoand microscopic particles over Kyrgyzstan is described in (Adushkin et al., 2012). In (Adushkin et al., 2015), the quantitative estimates of the aerosol's radiative forcing based on the empirical data on the physical and optical properties of aerosol during air pollutants transport into Central Asia are presented. An integrated study characterizing the properties and origin of small-scale particles over Central Asia is conducted in (Adushkin et al., 2016). The main focus was placed on studying particles during the summer when there are favorable conditions for the existence of ABCsregional-scale clusters of air pollution abundant in small particles of soot, sulfates, nitrates, fly ash, and other pollutants (Ramanathan and Crutzen, 2003; Ramanathan et al., 2007). The properties and behavior of small-scale particles in winter remain unexplored. The present paper is intended to fill this gap.

The first detailed studies of Central Asian mineral dust were undertaken in 1989 in the southwestern part of Tajikistan in the joint expedition of the scientists of the former Soviet Union and the United States (e.g., Sokolik and Golitsyn, 1993; Andronova et al., 1992; Isakov et al., 1992; Golitsyn and Gillette, 1993; and Hansen et al., 1993). Inter alia, particle-size distributions were obtained for the dust aerosol of the deserts of Central Asia (Andronova et al., 1992).

In this work, we present the results of acquiring and analyzing mineral nano- and microscopic particles above Kyrgyzstan during the winter season. Air sampling was carried out in January and February 2015 at a height of $\sim 1 \mathrm{~m}$ above the Earth's surface in the territory of the Teploklyuchenka lidar complex located at an altitude of $2050 \mathrm{~m}$ above sea level. This study is important for revealing the regularities of particle formation in the atmosphere of Central Asia, identifying the specificity of small-scale particles in the Central Asian region, and solving ecological and climate problems. 
(a)

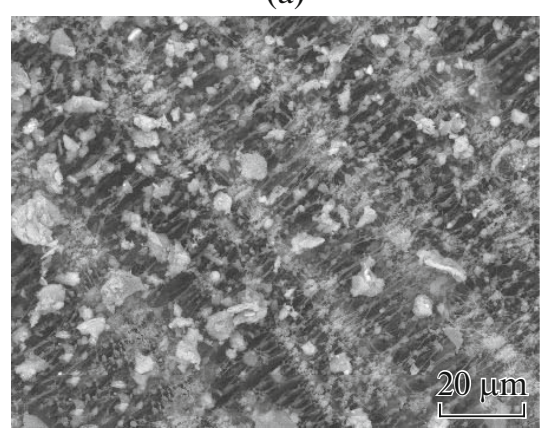

(b)

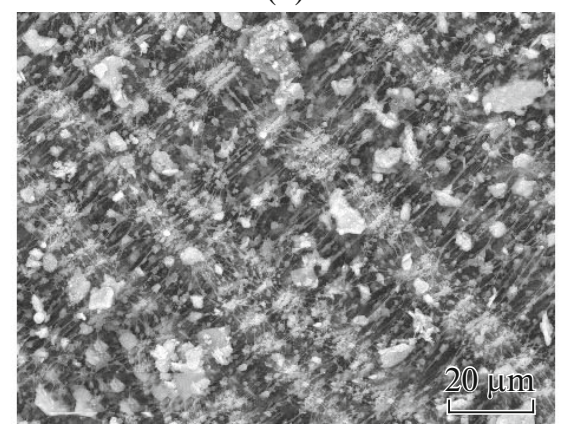

(c)

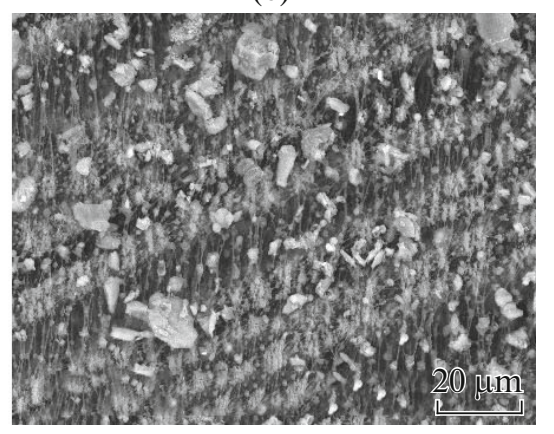

Fig 1. Electron images of small-scale particles from three different samples $(\mathrm{a}-\mathrm{c})$. Air samples were taken on February $8,2015$. Fine particles are seen sticking onto larger ones due to adhesion.

The particles were collected by URG-3000ABC particulate samplers with Teflon and quartz filters. Air was sampled for suspended chemical species in two particle size intervals-smaller than $10 \mu \mathrm{m}$ (samples PM $_{10}$ ) and smaller than $2.5 \mu \mathrm{m}$ (samples $\mathbf{P M}_{2.5}$ ) simultaneously in eight channels (four channels for particles smaller than $10 \mu \mathrm{m}$ and four channels for particles smaller than $2.5 \mu \mathrm{m}$ ). In this method it is required for the chemical background for the analyses by the X-ray fluorescence, radiometric, and gravimetric methods to be low.

This approach which does not separately consider nanoparticles (particles smaller than $1 \mu \mathrm{m}$, see (Adushkin et al., 2012)) can be used to reveal the sources of small-scale particles, especially as in the conditions of the Earth's atmosphere, the nanoparticles adhere to the larger (microscopic) particles (Fig. 1). Indeed, the formula for the adhesion characterizing the interaction between a particle of radius $a$ and the rough surface with allowance for the adsorption of the ambient air has the following form (Izvekova and Popel, 2014):

$$
F=\frac{A S^{2}}{24 \Omega^{2}}\left(\frac{r a}{r+a}+\frac{a}{\left(1+r S^{2} /(2 \Omega)\right)^{2}}\right),
$$

where $A$ is the Hamaker constant determined through the surface energy, $r$ is the characteristic size of the asperities of the surface, $S=\Omega / t$ is the surface purity introduced as the ratio of the diameter of the oxygen ion $\Omega=1.32 \times 10^{-8} \mathrm{~cm}$ to the thickness of the adsorbed layer $t$. The adhesion of the smaller particles to the larger ones is governed by the necessary condition of the predominance of the adhesion forces over the gravity force acting on a smaller particle. The calculations based on formula (1) show that in the normal conditions in the Earth's atmosphere (which correspond to $A=10^{-20}-10^{-19} \mathrm{~J}, S \sim 0.1$ (Izvekova and Popel, 2014)), the gravity force prevails over the adhesion force for the microscopic particles (i.e., particles larger than $1 \mu \mathrm{m})$. Hence, the nanoparticles can stick to the microscopic particles, in agreement with the observations (Fig. 1). For elucidating the role of the nanoparticles, the method that includes trapping the samples by the Petryanov filters (AFA-RSP-10) placed in the air samplers was used.

The small-scale particles contained in the filters were analyzed in the following way. At the first step, samples from the filters containing small-scale particles trapped by the filters were prepared for their subsequent analysis on a Philips XL 30 FEG raster electron microscope. For this purpose, circular specimens with a diameter of $10 \mathrm{~mm}$ were cut in the filters. These specimen stubs were separated from the filter and immediately placed on the surface of the carbon-containing pad coated with glue and fastened to the alumina holders of specimens of the Philips XL 30 FEG microscope. After this, the specimens were sprayed with an Au-Pd-containing substance, which led to the formation of a thin $(4-5 \mathrm{~nm})$ coating on the surface for improving the conductivity of the nonconductive material of the filters and for avoiding the local charging and damaging of the images. Imaging by the Philips XL 30 FEG electron microscope was used for gaining an idea about the quality of the specimens, i.e., for elucidating how much material is contained in the filters, how this material is distributed, and what is needed to increase the efficiency of studying the particles with the use of the Phillips XL 30 FEG microscope.

It was established that the particles are distributed on the filters fairly uniformly. The particle sizes range from fractions of a $\mu \mathrm{m}$ to about $10 \mu \mathrm{m}$. There are many clusters containing different minerals. Besides, organic material is present: spores and clusters containing fungi and/or mold which could be formed after the collection of the particles. The element analysis supported fairly uniform distributions of the silicates in the samples. However, at the same time, the samples also contain other minerals-carbonates, sulfates, and iron oxides (hydroxides).

The substance of the particles trapped by the filters was examined by the energy dispersion X-ray spectroscopy for determining the chemical composition. 
(a)

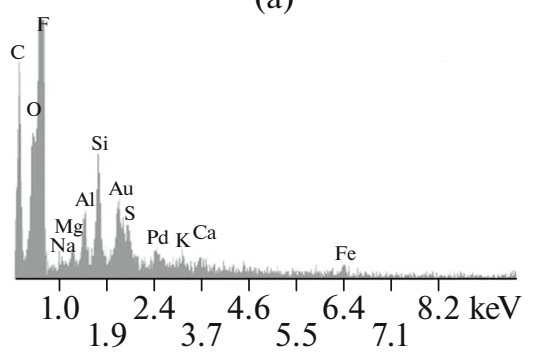

(b)

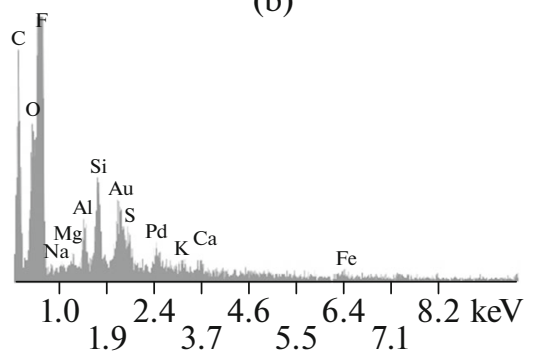

(c)

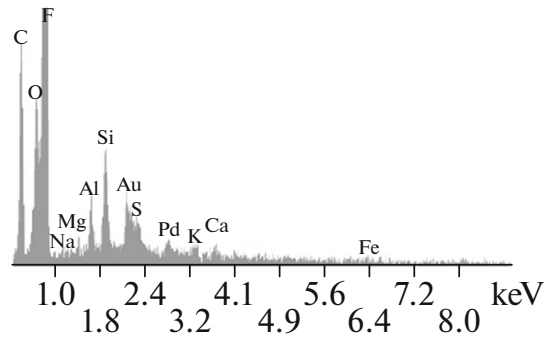

Fig. 2. Chemical composition of samples shown in Fig. 1 according to energy dispersion X-ray analysis.

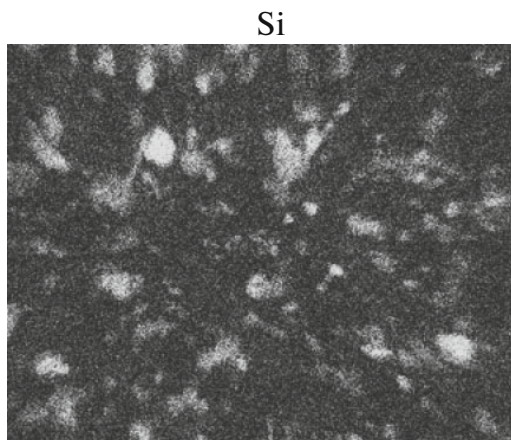

$\mathrm{Ca}$

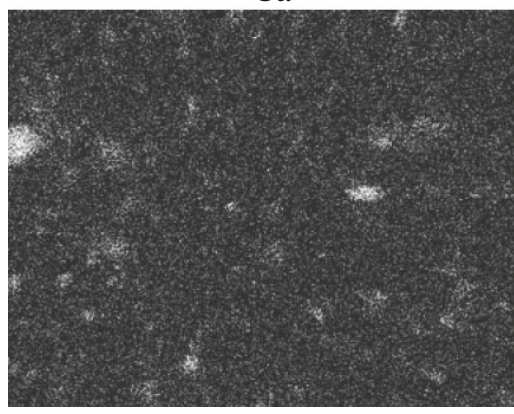

$\mathrm{Al}$

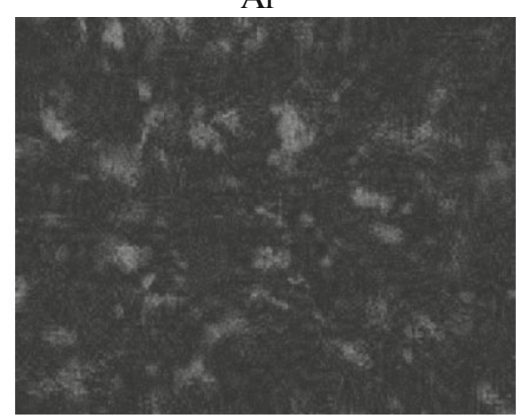

S

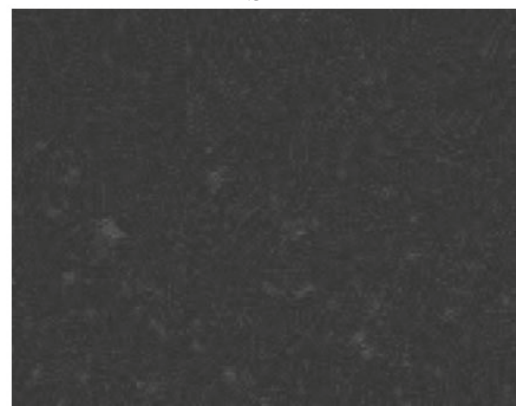

Fig 3. Example of chemical element mapping. Most significant elements are indicated.

The energy dispersive X-ray analysis was conducted on a Sapphire $\mathrm{Si}$ (Li) detector (EDAX) with liquid nitrogen cooling; the accelerating voltage was $15 \mathrm{kV}$. The typical area of a sample was diagnosed elementby-element. The diagrams reflecting the results of the energy dispersion analysis for the three samples are shown in Fig. 2. Figure 3 presents the examples of a mapping based on the chemical elements. The most significant elements are shown. By analyzing this figure, we can easily recognize the presence of silicates and differentiate them based on calcites and, e.g., calcium sulfate.

Generally, the energy dispersion analysis revealed three main groups of particles: (1) quartz-rich minerals (containing $\mathrm{O}$ and $\mathrm{Si}$ ); (2) feldspars containing $\mathrm{Si}$, $\mathrm{Al}, \mathrm{Mg}, \mathrm{Na}, \mathrm{Ca}$, and $\mathrm{K}$; and (3) layered silicates containing $\mathrm{Al}, \mathrm{Si}$, and $\mathrm{K}$ or $\mathrm{Mg}$. Separate occurrences of the minerals containing calcium carbonate are estab- lished. Besides, in some cases the particles contain biological material (Claviceps purpurea fungi, mold, etc.), which is likely to have appeared on the filters during the storage. This classification is illustrated by the data presented in Table 1. This table, which is compiled from the chemical composition data provided by the energy dispersion analysis, presents the chemical and mineralogical compositions of the mineral particles in the different samples based on the material collected on February 8, 2015. The symbols ***, **, and * in this table correspond to the large, intermediate, and small amounts (in terms of the mass fraction) of the chemical (mineral) elements making up more than $2 / 3$, from $1 / 3$ to $2 / 3$, and less than $1 / 3$ of the mass of the predominant element (mineral), respectively. The table shows that some samples contain chlorine. The presence of this chemical element is due to the material of the AFA-RSP-10 Petryanov fil- 
Table 1. Chemical and mineral compositions of mineral particles in different samples. Air sampling was conducted on February 8,2015

\begin{tabular}{|c|c|c|c|c|c|c|c|c|c|c|c|c|}
\hline Sample & $\mathrm{Si}$ & $\mathrm{S}$ & $\mathrm{Al}$ & $\mathrm{Ca}$ & K & $\mathrm{Fe}$ & $\mathrm{Mg}$ & $\mathrm{Na}$ & $\mathrm{Cl}$ & $\begin{array}{l}\text { Quartz- } \\
\text { rich } \\
\text { minerals }\end{array}$ & Feldspars & $\begin{array}{l}\text { Layered } \\
\text { silicates }\end{array}$ \\
\hline 0802P1-4_EDX & $* * *$ & $* *$ & $* *$ & $*$ & $*$ & $*$ & $*$ & $*$ & & $* * *$ & $* *$ & $* *$ \\
\hline 0802P1-5_EDX & $* * *$ & $* *$ & $* *$ & $*$ & $*$ & $*$ & $*$ & $*$ & $*$ & $* * *$ & $* *$ & $* *$ \\
\hline 0802P1-6_EDX & $* * *$ & $* *$ & $* *$ & $*$ & $*$ & $*$ & $*$ & $*$ & & $* * *$ & $* *$ & $* *$ \\
\hline 0802P1-7_EDX & $* * *$ & $*$ & $* *$ & $*$ & $*$ & $*$ & $*$ & $*$ & & $* * *$ & $* *$ & $* *$ \\
\hline 0802P1-8_EDX & $* * *$ & $* *$ & $* *$ & $*$ & $*$ & $*$ & $*$ & $*$ & & $* * *$ & $* *$ & $* *$ \\
\hline 0802P2-2_EDX & $* * *$ & $* *$ & $* *$ & $*$ & $*$ & $*$ & $*$ & $*$ & & $* * *$ & $* *$ & $* *$ \\
\hline 0802P2-3_EDX & $* * *$ & $* *$ & $* *$ & $*$ & $*$ & $*$ & $*$ & $*$ & & $* * *$ & $* *$ & $* *$ \\
\hline 0802P2-4_EDX & $* * *$ & $* *$ & $* *$ & $*$ & $*$ & $*$ & $*$ & & & $* * *$ & $* *$ & $* *$ \\
\hline 0802P2-5_EDX & $* * *$ & $* *$ & $* *$ & $*$ & $*$ & $*$ & $*$ & $*$ & & $* * *$ & $* *$ & $* *$ \\
\hline 0802P2-6_EDX & $* * *$ & & $* *$ & $*$ & $*$ & $*$ & $*$ & $*$ & & $* * *$ & $* *$ & $* *$ \\
\hline 0802P2-8_EDX & $* *$ & $*$ & $*$ & $* * *$ & $*$ & $*$ & $*$ & $*$ & $*$ & $* * *$ & $* *$ & $* *$ \\
\hline 0802P2-10_EDX & $* * *$ & $* * *$ & $* *$ & $*$ & $*$ & $*$ & $*$ & $* * *$ & & $* * *$ & $* *$ & $* *$ \\
\hline 0802P3-1_EDX & $* * *$ & $*$ & $* *$ & $*$ & $*$ & $*$ & $*$ & $*$ & & $* * *$ & $* *$ & $* *$ \\
\hline 0802P3-3_EDX & $* * *$ & $*$ & $* *$ & $*$ & * & $*$ & $*$ & $*$ & & $* * *$ & $* *$ & $* *$ \\
\hline 0802P3-4_EDX & $* * *$ & $* *$ & $* *$ & $*$ & * & $*$ & $*$ & $*$ & & $* * *$ & $* *$ & $* *$ \\
\hline 0802P3-6_EDX & $* * *$ & $*$ & $* *$ & $*$ & $*$ & $*$ & $*$ & $*$ & & $* * *$ & $* *$ & $* *$ \\
\hline 0802P3-7_EDX & $* * *$ & $*$ & $* *$ & $*$ & * & $*$ & $*$ & $*$ & & $* * *$ & $* *$ & $* *$ \\
\hline $0802 \mathrm{P} 3-\mathrm{CaCO}_{3}$ & $* * *$ & $*$ & $* *$ & $* * *$ & $*$ & $*$ & $*$ & $*$ & & $* * *$ & $* *$ & $* *$ \\
\hline 0802P3-Ca-S & $* * *$ & $* * *$ & $*$ & $* *$ & $* *$ & $*$ & $*$ & $*$ & & $* * *$ & $*$ & $*$ \\
\hline 0802P3-Fe & $* * *$ & * & * & $*$ & $*$ & $* * *$ & $*$ & $*$ & & $* * *$ & $*$ & $*$ \\
\hline
\end{tabular}

ters-chlorinated polyvinyl-chloride $\mathrm{PVC}-\mathrm{C}$, which is the base of the filters for these samples. A similar analysis was conducted for the teflon and quartz filters of the URG-2000ABC air inlets that were used for air sampling on February 8, 2015, which yielded similar results.

The synoptic situation on February 8, 2015 was the following. During the first half of the day, the weather over the eastern part of Kyrgyzstan which accommodates the Teploklyuchenka lidar complex was determined by a western intrusion when air pollution was formed by the particles originating from the Aral Sea basin, Western Kazakhstan, Karakum, and Kyzylkum deserts. In the troposphere at an altitude of $3-3.5 \mathrm{~km}$ (corresponding to the constant pressure surfaces of 700 and $500 \mathrm{hPa}$ ), there was a baric trough with the axis linking the territories of West Siberia, Kyrgyzstan, and Afghanistan. The eastern part of Kyrgyzstan was under the influence of the frontal periphery of the trough, whereas the western part of Kyrgyzstan was affected by the trough's rear part, which ensured the transfer of the midlatitude air masses at a height of $5.5 \mathrm{~km}(500 \mathrm{hPa})$ from the northern part of the Caspian Sea through the western sector of the air masstransport. The air flows had a western direction. The meteorological stations located in the eastern part of Issyk-Kul basin and in the Central Tien Shan recorded weak precipitation. In the western part of Kyrgyzstan, the precipitation had ceased and fog was observed.

At the end of the discussed day, the studied territory was located under the southwestern periphery of the anticyclone, which implied that, besides the air pollution source areas such as the Aral Sea basin, West Kazakhstan, Kara Kum, and Kyzyl Kum, particles were also transported from the sources in East Europe, the European part of Russia, West Siberia, and East Kazakhstan, including the Kazakh hummock region and Betpak-Dala, Moiynkum, and Taukum deserts. However, the anticyclone was rather weak; the frontal 

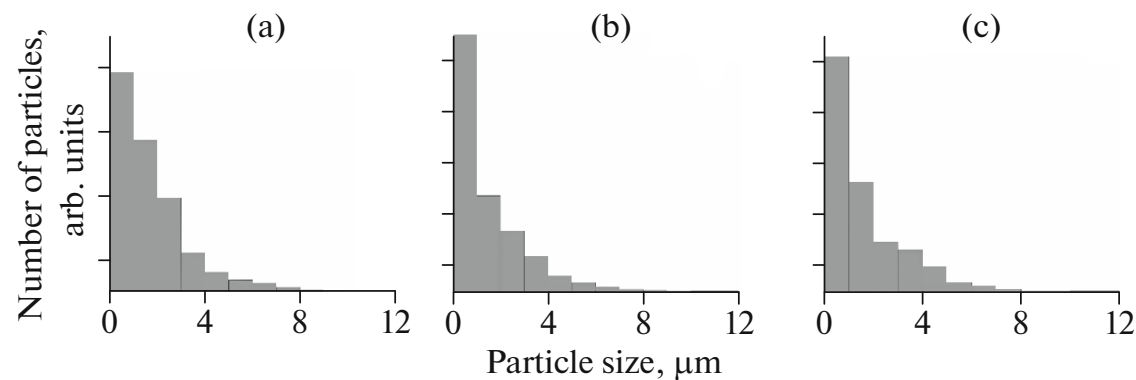

Fig. 4. Size distribution diagrams for particles from samples shown in Fig. 1

part of the baric ridge was at heights ranging from $1.5 \mathrm{~km}(850 \mathrm{hPa})$ to $3 \mathrm{~km}(700 \mathrm{hPa})$; very low wind velocities were noted, and the air flow had a southern direction. Precipitation had ceased throughout Kyrgyzstan.

The recurrence of the synoptic processes characterized, just as on February 8, 2015, by the southwestern and southern air mass flow directions, was $51.5 \%$ in January-February 2015. Hence, the considered chemical and mineral compositions of the mineral particles collected on February 8, 2015 are fairly typical for January-February 2015.

Figure 4 shows the size distribution diagrams for mineral particles from three typical samples. The first column on the left in each diagram in Fig. 4 indicates the number of nanoparticles. The analysis of the size distributions of the mineral particles in the filter yields the following results. In the particle size interval from $300 \mathrm{~nm}$ to $10 \mu \mathrm{m}$, the spectrum of particle size is most adequately described by the lognormal distribution with the median diameter $D_{\mathrm{m}}=2-3 \mu \mathrm{m}$ and variance of the $\log$ diameter $v^{2}=0.6-0.8$ for the different samples. These approximations give values that are fairly close to $D_{\mathrm{m}}=3.5-6 \mathrm{~km}$ and $v^{2}=0.5-0.8$ (Andronova et al., 1992), characterizing the distribution of the soilerosion-produced aerosol in the region of the experiment in Tajikistan in 1989 (Sokolik and Golitsyn, 1993; Andronova et al., 1992; Isakov et al., 1992; Golitsyn and Gillette, 1993; Hansen et al., 1993). This testifies to the probably similar origin of the mineral dust in the atmosphere over Kyrgyzstan. In the interval of particle sizes from 100 to $300 \mathrm{~nm}$, within each $50-\mathrm{nm}$ bin there are one or two randomly distributed particles. This is due to the fact that in the processing, the set of $\sim 5000$ particles is insufficient for conducting the statistical analysis of an area smaller than $300 \mathrm{~nm}$ for the particles described by lognormal distributions with the cited characteristics.

Thus, an empirical study of small mineral particles in the atmosphere over Kyrgyzstan in winter is carried out. It is shown that the substance of the studied particles corresponds to the quartz-rich minerals (containing $\mathrm{Si}$ and $\mathrm{O}$ ), feldspars containing $\mathrm{Si}, \mathrm{Al}, \mathrm{Mg}, \mathrm{Na}$, $\mathrm{Ca}$, and $\mathrm{K}$; layered silicates containing $\mathrm{Al}, \mathrm{Si}$, and $\mathrm{K}$ or
$\mathrm{Mg}$; minerals containing calcium carbonate, etc. Generally, there is a certain correspondence in the mineral particle compositions in the atmosphere over Kyrgyzstan and in the other regions of Central Asia. The size distributions of the particles are constructed. These distributions agree with the results of studying the properties of the dust aerosol in the deserts of Central Asia in the southwestern part of Tajikistan (Andronova et al., 1992).

\section{ACKNOWLEDGMENTS}

The work was partially supported by the International Science and Technology Center (project no. KR-2015).

\section{REFERENCES}

Adushkin, V.V., Popel, S.I., Chen, B.B., Weidler, P.G., and Friedrich, F., Experimental study of small-scale particles in atmospheric brown clouds, Dokl. Earth Sci., 2012, vol. 447, no. 2, pp. 1317-1321.

Adushkin, V.V., Chen, B.B., Popel, S.I., Weidler, P.G., Imashev, S.A., Losseva, T.V., Sverdlik, L.G., and Friedrich, F., Radiative forcing of aerosols in Central Asia, Dokl. Earth Sci., 2015, vol. 460, no. 2, pp. 137-141.

Adushkin, V.V., Chen, B.B., Popel, S.I., Weidler, P.G., Friedrich, F., and Izvekova, Yu.N., Properties and origin of small particles in the atmosphere of Central Asia, Dokl. Earth Sci., 2016, vol. 466, no. 2, pp. 177-182.

Anastasio, C. and Martin, S.T., Atmospheric nanoparticles, in Nanoparticles and the Environment, Washington: Mineralogical Society of America, 2001, chapter 8, pp. 293-349.

Andronova, A.V., Belan, B.D., Gillette, D.A., Isakov, A.A., Zhukov, V.M., Zhukovskii, D.A., Kolomiets, S.M., Panchenko, M.V., Sviridenkov, M.A., Smirnov, V.V., and Sokolik, I.N., Microphysical characteristics of dust aerosol based on the results of the Soviet-American experiment (Tadzhikistan, 1989), Fiz. Atmos. Okeana, 1992, vol. 28, no. 8 , pp. $798-804$.

Golitsyn, G. and Gillette, D.A., Introduction: A joint Soviet-American experiment for the study of Asian desert dust and its impact on local meteorological conditions and climate, Atmos. Environ., 1993, vol. 27A, no. 16, pp. 24672470 . 
Hansen, A.D.A., Kapustin, V.N., Kopeikin, V.M., Gillette, D.A., and Bodhaine, B.A., Optical absorption by aerosol black carbon and dust in a desert region of Central Asia, Atmos. Environ., 1993, vol. 27A, no. 16, pp. 25272531 .

Isakov, A.A., Nazarov, B.I., Panchenko, M.V., Pirogov, S.M., Romashova, E.V., Sviridenkov, M.A., Sokolik, I.N., Terpugova, S.A., Fedorova, E.K., Chistyakova, E.I. and Shukurov, A.Kh., Optical properties of dust subtractions, Fiz. Atmos. Okeana, 1992, vol. 28, no. 8, pp. 805-812.

Izvekova, Yu. and Popel, S., Adhesion of fine particles in nature, Russia and Germany. Sci. Humboldt Mag., 2014, nos. 7-8, pp. 70-74.

Kondrat'ev, K.Ya., Moskalenko, N.I., and Pozdnyakov, D.V., Atmosfernyi aerozol' (Atmospheric Aerosol), Leningrad: Gidrometeoizdat, 1983.
Popel, S.I., Kopnin, S.I., Yu, M.Y., and Ma, J.X., and Huang Feng, The effect of microscopic charged particulates in space weather, J. Phys. D: Appl. Phys., 2011, vol. 44, 174036.

Ramanathan, V. and Crutzen, P.J., New directions: "Atmospheric Brown Clouds," Atmos. Environ., 2003, vol. 37, no. 28, pp. 4033-4035.

Ramanathan, V., Ramana, M.V., Roberts, G., Kim, D., Corrigan, C., Chung, C., and Winker, D., Warming trends in Asia amplified by brown cloud solar absorption, Nature, 2007, vol. 448, pp. 575-578.

Sokolik, I. and Golitsyn, G., Investigation of optical and radiative properties of atmospheric dust aerosols, Atmos. Environ., Part A, 1992, vol. 27A, no. 16, pp. 2509-2517.

Translated by M. Nazarenko 


\section{Repository KITopen}

Dies ist ein Postprint/begutachtetes Manuskript.

Empfohlene Zitierung:

Adushkin, V. V.; Chen, B. B.; Popel, S. I.; Dubinskii, A. Y.; Weidler, P. G.; Friedrich, F. Experimental Study of Small-Scale Mineral Particles in the Atmosphere of Central Asia. 2018. Izvestiya / Physics of the solid earth, 54

doi:10.1134/S1069351318020015

Zitierung der Originalveröffentlichung:

Adushkin, V. V.; Chen, B. B.; Popel, S. I.; Dubinskii, A. Y.; Weidler, P. G.; Friedrich, F. Experimental Study of Small-Scale Mineral Particles in the Atmosphere of Central Asia. 2018. Izvestiya / Physics of the solid earth, 54 (2), 330-335. doi:10.1134/S1069351318020015 